ARTICLE

https://doi.org/10.1038/s41467-019-13560-0

\title{
Near $100 \%$ CO selectivity in nanoscaled iron-based oxygen carriers for chemical looping methane partial oxidation
}

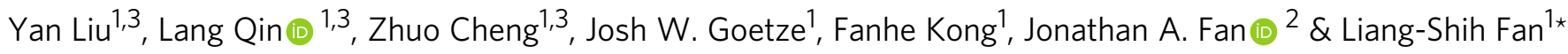

Chemical looping methane partial oxidation provides an energy and cost effective route for methane utilization. However, there is considerable $\mathrm{CO}_{2}$ co-production in current chemical looping systems, rendering a decreased productivity in value-added fuels or chemicals. In this work, we demonstrate that the co-production of $\mathrm{CO}_{2}$ can be dramatically suppressed in methane partial oxidation reactions using iron oxide nanoparticles embedded in mesoporous silica matrix. We experimentally obtain near $100 \% \mathrm{CO}$ selectivity in a cyclic redox system at $750-935^{\circ} \mathrm{C}$, which is a significantly lower temperature range than in conventional oxygen carrier systems. Density functional theory calculations elucidate the origins for such selectivity and show that low-coordinated lattice oxygen atoms on the surface of nanoparticles significantly promote $\mathrm{Fe}-\mathrm{O}$ bond cleavage and $\mathrm{CO}$ formation. We envision that embedded nanostructured oxygen carriers have the potential to serve as a general materials platform for redox reactions with nanomaterials at high temperatures.

\footnotetext{
${ }^{1}$ Department of Chemical and Biomolecular Engineering, The Ohio State University, 151W Woodruff Ave, Columbus, OH 43210, USA. ${ }^{2}$ Department of Electrical Engineering, Ginzton Laboratory, Spilker Engineering and Applied Sciences, Stanford University, 348 Via Pueblo Mall, Stanford, CA 94305, USA.

${ }^{3}$ These authors contributed equally: Yan Liu, Lang Qin, Zhuo Cheng *email: fan.1@osu.edu
} 
S yngas, i.e., $\mathrm{CO}$ and $\mathrm{H}_{2}$, is an important intermediate for producing fuels and value-added chemicals from methane via Fischer-Tropsch or other synthesis techniques ${ }^{1}$. Syngas has been produced commercially by steam reforming, autothermal reforming, and partial oxidation of methane for many decades $^{2}$. However, an improvement of its energy consumption, environmental impact, and associated production cost has always been of interest. This has prompted the investigation into alternative routes that can avoid the use of air separation units for producing purified oxygen and are more effective in $\mathrm{CO}_{2}$ emission control. It is also of interest to reduce the operating temperature of these processes, which are generally endothermic and traditionally require temperatures of $900{ }^{\circ} \mathrm{C}$ or higher to attain high reactant conversion rates. The use of high temperatures is problematic because the thermodynamic driving force for carbon deposition, and thus materials obliteration, can be accelerated ${ }^{3}$. Current approaches to reducing reaction temperatures while avoiding side product formation require noble metals such as $\mathrm{Pt}$, $\mathrm{Pd}$, or $\mathrm{Au}$, which leads to dramatic increases in cost $^{4}$.

Chemical looping methane partial oxidation ${ }^{5}$ (CLPO) is an emerging approach that overcomes the above-mentioned shortcomings for syngas production. A CLPO process involves redox reactions taking place in two interconnected reactors: a reducer (or fuel reactor) and an oxidizer (also referred to as air reactor), shown in Fig. 1a. In contrast to conventional fossil fuel gasification and reforming processes, CLPO eliminates the need for an air separation unit, water-gas shift reactor, and acid gas removal unit. It has the potential to directly produce high-quality syngas with desirable $\mathrm{H}_{2}$ :CO ratios. The core of CLPO using natural gas as the feedstock involves complex redox reactions in which methane molecules adsorb and dissociate on metal oxide oxygen carrier surfaces. It also involves internal lattice oxygen ion diffusion in which oxygen vacancy creation and annihilation occurs. These reactions can be engineered to withstand thousands of redox cycles 5 .

The recent progress in chemical looping technology for partial oxidation has advanced to the stage where successful pilot operation has been demonstrated and proven to be highly efficient with a minimal energy penalty in the process applications ${ }^{6}$.
In this technology, the highest CO selectivity that the CLPO can reach is thermodynamically limited to $90 \%$ with accompanied $10 \% \mathrm{CO}_{2}$ generation. It is recognized that the $\mathrm{CO}_{2}$ reduction in low purity syngas is extremely challenging and energy consuming, as $\mathrm{CO}_{2}$ is among the most chemically stable carbon-based molecules ${ }^{7}$. This $10 \%$ of $\mathrm{CO}_{2}$ in syngas can significantly reduce the productivity of value-added fuels or chemicals generated. Breaking away from the $90 \%$ CO yield limits to achieve near $100 \%$ CO selectivity requires a different consideration from the metal oxide materials design and synthesis perspective.

We report an approach to metal oxide oxygen carrier engineering for CLPO by designing and synthesizing nanoscale iron oxide carriers $^{8}$ embedded in mesoporous silica SBA-15 $\left(\mathrm{Fe}_{2} \mathrm{O}_{3} @ S B A-15\right)$. Mesoporous silica is an engineered nanomaterial that has high surface area, ordered pore structures, and high tunability of morphology. Its unique properties have attracted broad attention in a number of applications such as environmental treatment, catalysis, and biomedical engineering ${ }^{9-17}$. SBA15 is a common mesoporous silica that has perpendicular nanochannels with a narrow pore size distribution which is suitable for nanoparticle separation and gas penetration. A schematic of our materials platform is outlined in Fig. 1a. We experimentally achieve a high CO selectivity $>99 \%$, which is by far the highest in CLPO systems (Fig. 1b). We also find that cyclic methane partial oxidation with nanoscale oxygen carrier materials can be performed with high selectivity at temperatures as low as $750{ }^{\circ} \mathrm{C}$. These findings underscore the strong size-dependent effects of metal oxide oxygen carriers at the nanoscale on syngas selectivity and reactant conversion in redox processes. This work will have broader impacts not only on CLPO, but also on other chemical looping applications such as carbonaceous fuel conversion and utilization.

\section{Results}

Characteristics of $\mathrm{Fe}_{2} \mathrm{O}_{3} @ S B A-15$. Figure 2 shows the transmission electron microscope (TEM) images of $\mathrm{Fe}_{2} \mathrm{O}_{3} @ S B A-15$ before and after redox cycles with no obvious morphological distinction. Nanoparticles with a size of $3-5 \mathrm{~nm}$ can be identified

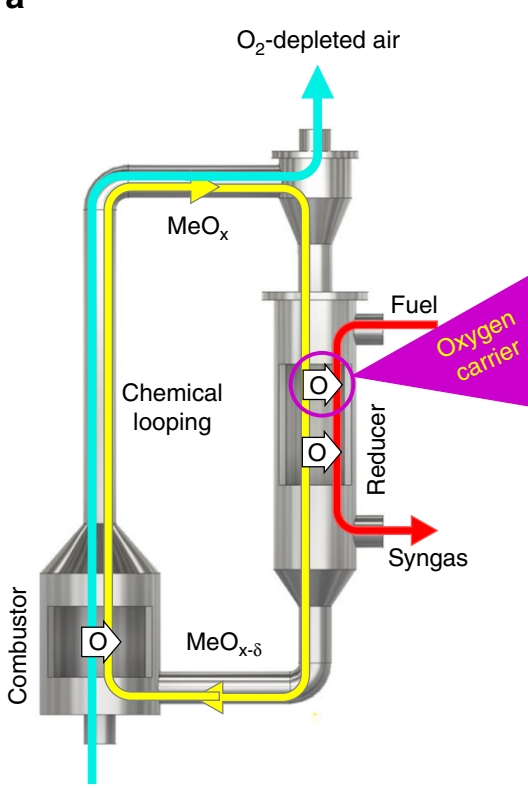

b

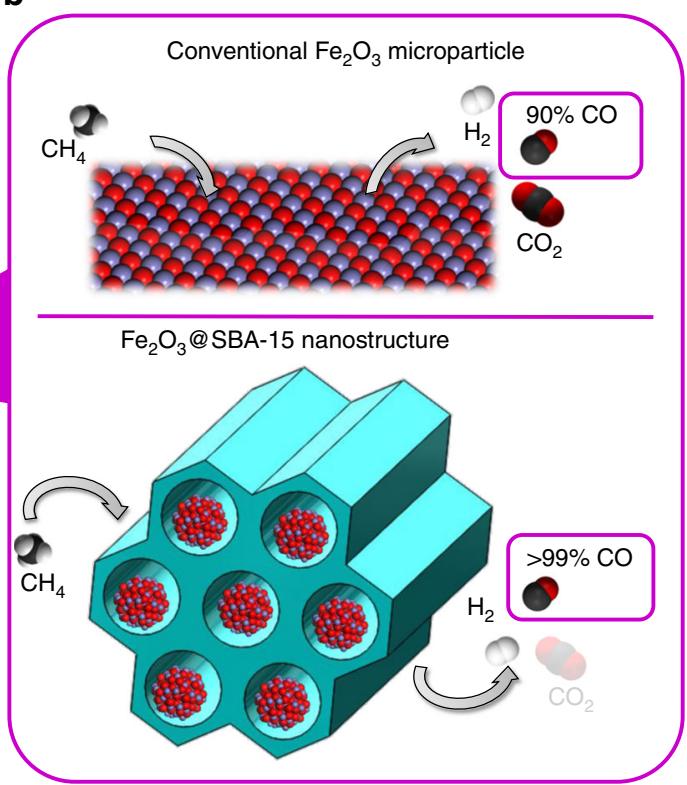

Fig. 1 Chemical looping partial oxidation with methane. a Schematic of the chemical looping partial oxidation process; $\mathbf{b}$ structure and CO selectivity in conventional oxygen carrier vs $\mathrm{Fe}_{2} \mathrm{O}_{3} @ S B A-15$ oxygen carrier. 
as $\alpha-\mathrm{Fe}_{2} \mathrm{O}_{3}$ based on lattice fringes measurement in which $a=$ $b=5.038 \AA$ and $c=13.772 \AA$. Element mapping is presented in Supplementary Fig. 1, suggesting that $\mathrm{Fe}_{2} \mathrm{O}_{3}$ nanoparticles are embedded in SBA-15 nanochannels. The TEM images also confirm that the nanoparticles remain embedded in SBA-15 nanochannels with identical morphology after 75 redox cycles. The particle size slightly increases to $5-8 \mathrm{~nm}$ after 75 redox cycles due to unavoidable morphology evolution. This result indicates the high stability of $\mathrm{Fe}_{2} \mathrm{O}_{3} @ S B A-15$ at high temperatures.

The mesoporous silica SBA-15 (Supplementary Fig. 2) exhibits a surface area of $550 \mathrm{~m}^{2} \mathrm{~g}^{-1}$, a uniform pore size of $8 \mathrm{~nm}$, and a pore volume of $0.66 \mathrm{~cm}^{3} \mathrm{~g}^{-1}$ (Supplementary Methods). The pore volume decreases to $0.52 \mathrm{~cm}^{3} \mathrm{~g}^{-1}$ which is $23 \%$ less than SBA-15 after $\mathrm{Fe}_{2} \mathrm{O}_{3}$ nanoparticle loading, implying a $\mathrm{Fe}_{2} \mathrm{O}_{3}$ nanoparticle volume loading of $\sim 20 \%$. The average pore size remains at $8 \mathrm{~nm}$ with a minor decrease in magnitude, indicating that the silica nanochannels are partially filled by $\mathrm{Fe}_{2} \mathrm{O}_{3}$ nanoparticles.

In comparison, Supplementary Fig. 3a, c suggests that the unsupported $\mathrm{Fe}_{2} \mathrm{O}_{3}$ nanoparticles are agglomerated with a wide size distribution of 50-100 nm. Supplementary Fig. 3b, d reveals that the nanoparticles will evolve to microparticles of $1-10 \mu \mathrm{m}$

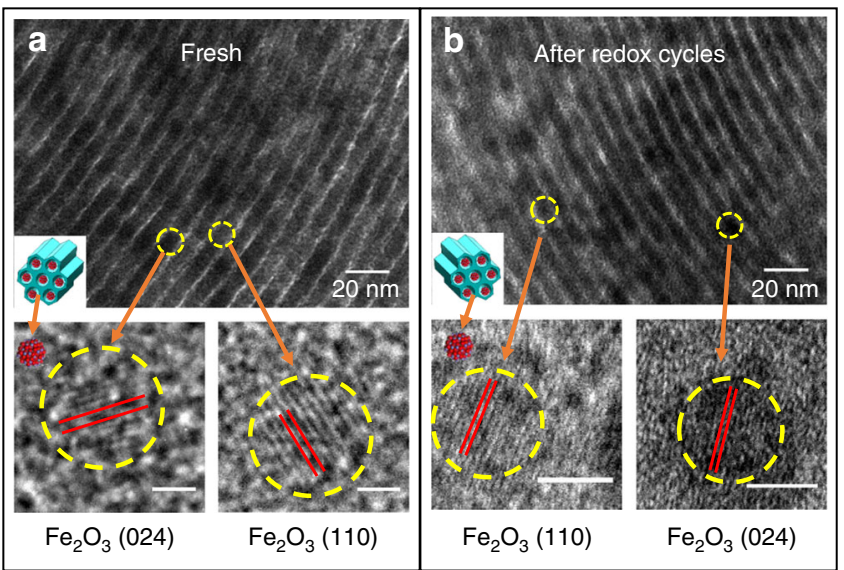

Fig. 2 Morphological characteristics of $\mathrm{Fe}_{2} \mathrm{O}_{3} @ S B A-15$. a Fresh $\mathrm{Fe}_{2} \mathrm{O}_{3} @ S B A-$ 15 and HR-TEM images of two typical $\mathrm{Fe}_{2} \mathrm{O}_{3}$ nanoparticles (Scale bar represents $1 \mathrm{~nm}$ ); b $\mathrm{Fe}_{2} \mathrm{O}_{3} @ S B A-15$ after 75 redox cycles and HR-TEM images of two typical $\mathrm{Fe}_{2} \mathrm{O}_{3}$ nanoparticles (Scale bar represents $5 \mathrm{~nm}$ ).

after 75 redox cycles. On the other hand, the morphology of $\mathrm{Fe}_{2} \mathrm{O}_{3} @$ SBA-15 arrays before and after 75 redox cycles (Supplementary Fig. 3e, f) remain almost unchanged, indicating high recyclability of $\mathrm{Fe}_{2} \mathrm{O}_{3} @ \mathrm{SBA}-15$ at both nanoscale and microscale.

Methane CLPO with $\mathbf{F e}_{2} \mathbf{O}_{3} @ S B A-15$. The reactivity and recyclability test results are shown in Fig. 3. A stable $\mathrm{CO}_{2}$ concentration of $<0.7 \% \mathrm{go}^{-1}$ is observed in $\mathrm{Fe}_{2} \mathrm{O}_{3} @ S B A-15$ throughout methane partial oxidation, indicating a high syngas selectivity higher than $99.3 \%$. In unsupported $\mathrm{Fe}_{2} \mathrm{O}_{3}, \mathrm{CO}_{2}$ formation is observed to increase with temperature, resulting in an average selectivity less than $87 \%$. In the range of $750-935^{\circ} \mathrm{C}, \mathrm{CO}$ concentration from $\mathrm{Fe}_{2} \mathrm{O}_{3} @ \mathrm{SBA}-15$ is over 200\% higher than unsupported $\mathrm{Fe}_{2} \mathrm{O}_{3}$, suggesting a near $100 \% \mathrm{CO}$ selectivity with significantly higher $\mathrm{CO}$ conversion rate.

Over 75 continuous redox cycles were carried out on both $\mathrm{Fe}_{2} \mathrm{O}_{3}$ samples with and without SBA-15 support (Supplementary Fig. 4). Five typical TGA redox cycles are shown in Fig. 3b. The high recyclability is consistent with TEM observation. $\mathrm{Fe}_{2} \mathrm{O}_{3} @ S B A-15$ not only has a high conversion rate, but is stable at high temperatures. This suggests that the separation of nanoparticles is essential in maintaining high CO selectivity, reactivity, and recyclability. At $800{ }^{\circ} \mathrm{C}$, the conversion rate of $\mathrm{Fe}_{2} \mathrm{O}_{3} @ S B A-15$ is $67 \%$ higher than unsupported $\mathrm{Fe}_{2} \mathrm{O}_{3}$. The morphology of post redox nanoparticles can be found in Fig. 2b, where $\mathrm{Fe}_{2} \mathrm{O}_{3} @ S B A-15$ nanochannels remain almost identical to fresh samples. This demonstrates the high stability and antisintering effect of dispersed nanostructures at high temperatures. The average pore size of $\mathrm{Fe}_{2} \mathrm{O}_{3} @ S B A-15$ is $7.6 \mathrm{~nm}$ after 75 redox cycles (Supplementary Fig. 5), which confirms high cyclic stability.

The methane conversion and syngas selectivity of both unsupported $\mathrm{Fe}_{2} \mathrm{O}_{3}$ and $\mathrm{Fe}_{2} \mathrm{O}_{3} @ S B A-15$ were also evaluated in a quartz U-tube ( $1 \mathrm{~cm}$ diameter) fixed bed reactor. As illustrated in Supplementary Fig. 6, a high selectivity near $100 \%$ in $\mathrm{Fe}_{2} \mathrm{O}_{3} @$ SBA-15 is confirmed in both TGA and fixed bed reactor and a higher methane conversion is also obtained compared with unsupported $\mathrm{Fe}_{2} \mathrm{O}_{3}$ with different weight hourly space velocity (WHSV).

Size-dependent reaction modeling. To gain mechanistic insight into the role of the nanostructures in $\mathrm{CO}$ selectivity enhancement of $\mathrm{Fe}_{2} \mathrm{O}_{3} @ S B A-15$, first-principles calculations were performed

b
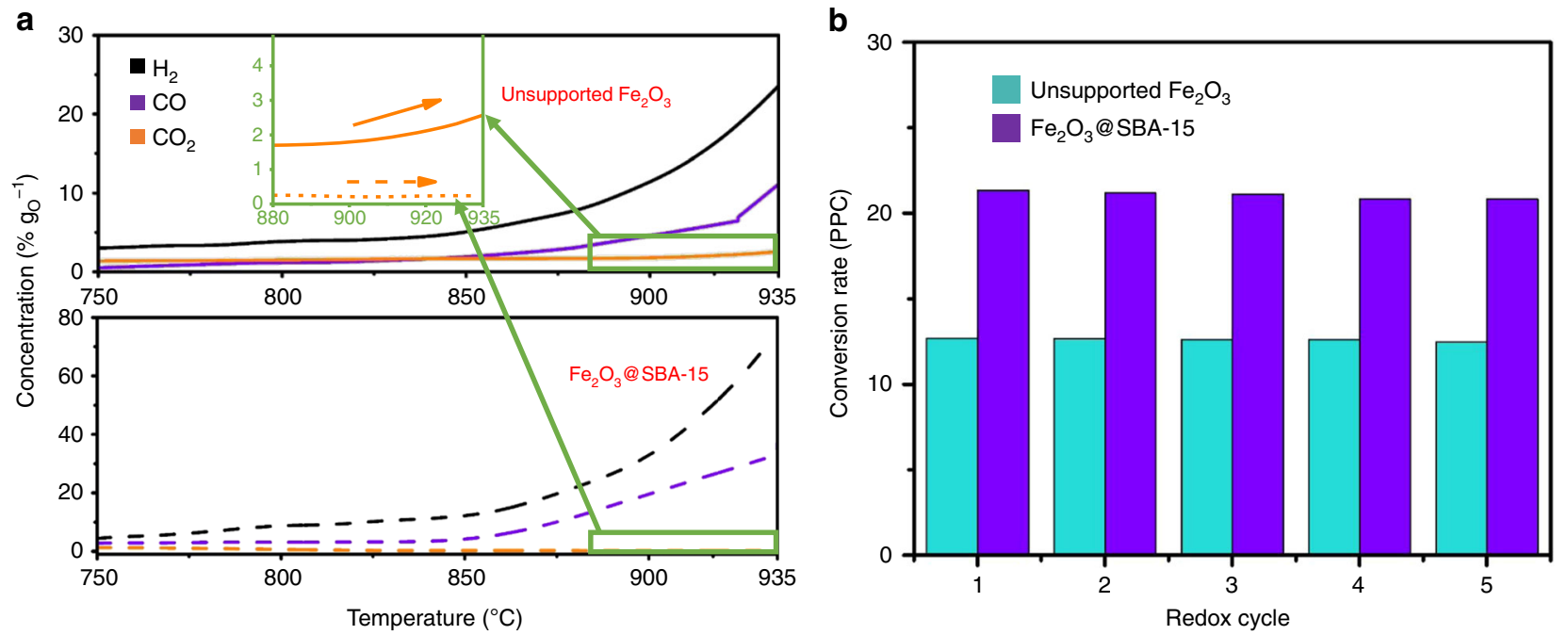

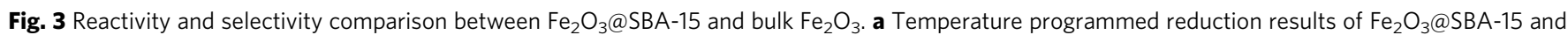
unsupported $\mathrm{Fe}_{2} \mathrm{O}_{3} ; \mathbf{b}$ conversion rate during redox at $800^{\circ} \mathrm{C}$. 
within the framework of density functional theory (DFT) using the Vienna Ab Initio Simulation Package (VASP) ${ }^{18-20}$. To take into consideration realistic experimental conditions $\left(800^{\circ} \mathrm{C}\right.$ for $\mathrm{CH}_{4}$ partial oxidation), the temperature effect is included by explicitly taking into account adsorbed $\mathrm{CH}_{4}$ molecules in terms of $\mathrm{ab}$ initio atomistic thermodynamics. The theoretical description requires the size and geometry of the model to be as realistic as possible, for direct comparison with experimental samples. However, modeling $\left(\mathrm{Fe}_{2} \mathrm{O}_{3}\right)_{n}$ nanoparticles of realistic size $(>3 \mathrm{~nm}$ ) by first-principles calculations is very demanding and the global optimization is hardly feasible. In this work, $\left(\mathrm{Fe}_{2} \mathrm{O}_{3}\right)_{60}$ $(\sim 2 \mathrm{~nm})$ is modeled as the largest nanoparticle to examine the size effect. Figure 4 shows calculated energies of $\mathrm{CH}_{4}$ adsorption on $\mathrm{Fe}$ atop site and $\mathrm{O}$ atop site of $\left(\mathrm{Fe}_{2} \mathrm{O}_{3}\right)_{n}$ nanoparticles as a function of $n$, and the corresponding adsorption geometries are described in Supplementary Fig. 7. The data of the previous computational study on $\mathrm{CH}_{4}$ adsorption on $\mathrm{Fe}_{2} \mathrm{O}_{3}$ (001) surface are given by the filled circle ${ }^{21}$. It can be seen that $\mathrm{CH}_{4}$ adsorption energies dramatically decrease with increasing number, $n$ when the sizes of $\mathrm{Fe}_{2} \mathrm{O}_{3}$ nanoparticles are at a relatively small scale. However, they decrease slowly with increasing $n$ when the sizes are at relatively large scale. The strongest adsorption on $\left(\mathrm{Fe}_{2} \mathrm{O}_{3}\right)_{4}$ is $\mathrm{CH}_{4}$ binding at the $\mathrm{Fe}$ atop site with an adsorption energy of $66.2 \mathrm{~kJ} \mathrm{~mol}^{-1}$. The second stable configuration is $\mathrm{CH}_{4}$ adsorption at the $\mathrm{O}$ atop site of $\left(\mathrm{Fe}_{2} \mathrm{O}_{3}\right)_{4}$ with an adsorption energy of $35.1 \mathrm{~kJ} \mathrm{~mol}^{-1}$.

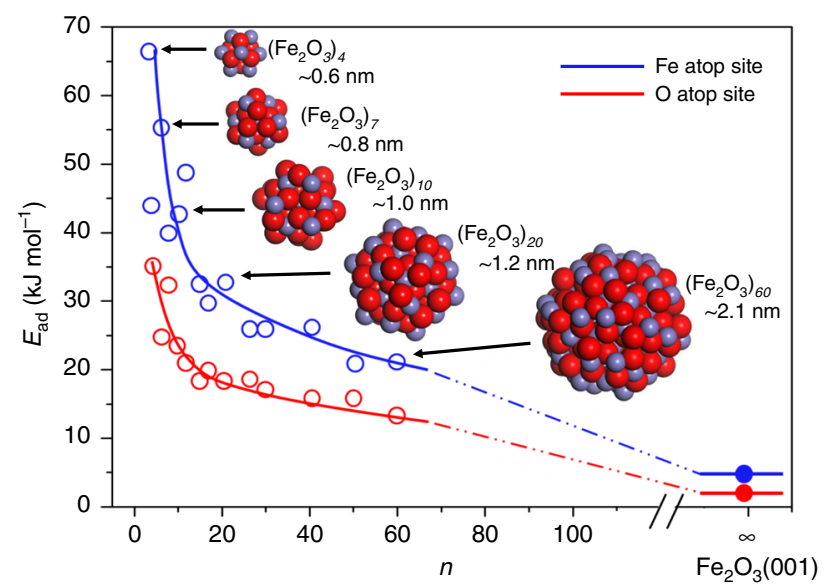

Fig. 4 Calculated energies of $\mathrm{CH}_{4}$ adsorption. $E_{\text {ad }}\left(\mathrm{kJ} \mathrm{mol}^{-1}\right)$, on Fe atop site and $\mathrm{O}$ atop site of $\left(\mathrm{Fe}_{2} \mathrm{O}_{3}\right)_{n}$ nanoparticles as a function of $n$. The adsorption trends are shown by the blue and red lines.
When $n$ increases from 4 to 60 , the Fe atop adsorption becomes weaker with $43.9 \mathrm{~kJ} \mathrm{~mol}^{-1}$ lower adsorption energy. However, the adsorption at the $\mathrm{Fe}$ atop site and the $\mathrm{O}$ atop site of $\left(\mathrm{Fe}_{2} \mathrm{O}_{3}\right)_{60}$ nanoparticles is still stronger than adsorption on $\mathrm{Fe}_{2} \mathrm{O}_{3}(001)$ surface, as shown in Fig. 5. This is because the average coordination number of surface $\mathrm{Fe}$ atoms in $\left(\mathrm{Fe}_{2} \mathrm{O}_{3}\right)_{n}$ nanoparticle is smaller than that on $\mathrm{Fe}_{2} \mathrm{O}_{3}$ (001) surface. The undercoordination results in an upward shift of the Fe d-band, yielding high binding energies.

In chemical looping partial oxidation process, $\mathrm{CH}_{4}$ is initially dissociated over oxygen carriers to form hydrogen and $\mathrm{CH}_{x}$ radicals. Then the $\mathrm{CH}_{x}$ radicals are oxidized by lattice oxygen to generate $\mathrm{CO}$ or $\mathrm{CO}_{2}{ }^{4,22}$. Since the energy and geometry of $\mathrm{CH}_{4}$ adsorption on $\left(\mathrm{Fe}_{2} \mathrm{O}_{3}\right)_{20}$ are similar with $\mathrm{CH}_{4}$ adsorption on $\left(\mathrm{Fe}_{2} \mathrm{O}_{3}\right)_{60}, \mathrm{Fe}_{40} \mathrm{O}_{60}(n=20)$ nanoparticles are chosen as the model to calculate the reaction barriers of $\mathrm{CH}_{4}$ dissociation and oxidation. The energy profile was mapped out as shown in Fig. 5. The energy barrier for the first step of $\mathrm{CH}_{4}$ dissociation on $\mathrm{Fe}_{40} \mathrm{O}_{60}$ is $135.8 \mathrm{~kJ} \mathrm{~mol}^{-1}$, which is $55.7 \mathrm{~kJ} \mathrm{~mol}^{-1}$ lower than that of $\mathrm{CH}_{4}$ dissociation on the $\mathrm{Fe}_{2} \mathrm{O}_{3}$ (001) surface. $\mathrm{Fe}_{40} \mathrm{O}_{60}$ also exhibit higher activity for $\mathrm{CH}_{3}, \mathrm{CH}_{2}$, and $\mathrm{CH}$ dissociation due to the lower barriers, compared with the $\mathrm{Fe}_{2} \mathrm{O}_{3}$ (001) surface. It indicates that nanostructured $\mathrm{Fe}_{2} \mathrm{O}_{3}$ facilitates $\mathrm{CH}_{4}$ conversion compared with bulk $\mathrm{Fe}_{2} \mathrm{O}_{3}$, which is in good agreement with TGA and fixed bed test. After methane dissociation, all $\mathrm{C}-\mathrm{H}$ bonds are cleaved to generate a carbon atom and four hydrogen atoms. $\mathrm{Fe}_{40} \mathrm{O}_{60}$ has three chemically distinguishable types of lattice oxygen atoms: 2-fold coordinated lattice oxygen $\mathrm{O}_{2 \mathrm{C}}$, 3-fold coordinated lattice oxygen $\mathrm{O}_{3 \mathrm{C}}$, and 4-fold coordinated lattice oxygen $\mathrm{O}_{\text {sub }}$. As such, there are three reaction pathways for $\mathrm{CO}$ formation as shown in Supplementary Fig. 8. The calculated barriers for $\mathrm{CO}_{2 \mathrm{C}}, \mathrm{CO}_{3 \mathrm{C}}$, and $\mathrm{CO}_{\text {sub }}$ formation are $37.2 \mathrm{~kJ} \mathrm{~mol}^{-1}$, $69.6 \mathrm{~kJ} \mathrm{~mol}^{-1}$, and $58.5 \mathrm{~kJ} \mathrm{~mol}^{-1}$, respectively. This result indicates $\mathrm{C}$ binding to $\mathrm{O}_{2 \mathrm{C}}$ is the most favorable path, compared with $\mathrm{C}$ binding to $\mathrm{O}_{3 \mathrm{C}}$ and $\mathrm{O}_{\text {sub }}$ because $\mathrm{Fe}-\mathrm{O}$ bonds of lowcoordinated lattice oxygen atoms are easier to break than highcoordinated lattice oxygen atoms. In contrast to $\mathrm{Fe}_{40} \mathrm{O}_{60}$, all lattice oxygen atoms in the topmost atomic layer of the $\mathrm{Fe}_{2} \mathrm{O}_{3}$ (001) surface are three-coordinated atoms. Thus, the carbon atom on the $\mathrm{Fe}_{2} \mathrm{O}_{3}$ (001) surface converts to $\mathrm{CO}$ only via binding to $\mathrm{O}_{3 \mathrm{C}}$, leading to a relatively high barrier of $61.2 \mathrm{~kJ} \mathrm{~mol}^{-1}$ as shown in Fig. 5.

The formed $\mathrm{CO}$ may further react with surface lattice $\mathrm{O}$ atoms to form $\mathrm{CO}_{2}^{21,22}$. For the $\mathrm{Fe}_{40} \mathrm{O}_{60}$ nanoparticle, the formation of $\mathrm{CO}_{2}$ needs to overcome a barrier of $148.9 \mathrm{~kJ} \mathrm{~mol}^{-1}$, which is $30.4 \mathrm{~kJ} \mathrm{~mol}^{-1}$ higher than that of $\mathrm{CO}_{2}$ formation on $\mathrm{Fe}_{2} \mathrm{O}_{3}(001)$ surface. The high barrier with respect to $\mathrm{CO}_{2}$ formation on

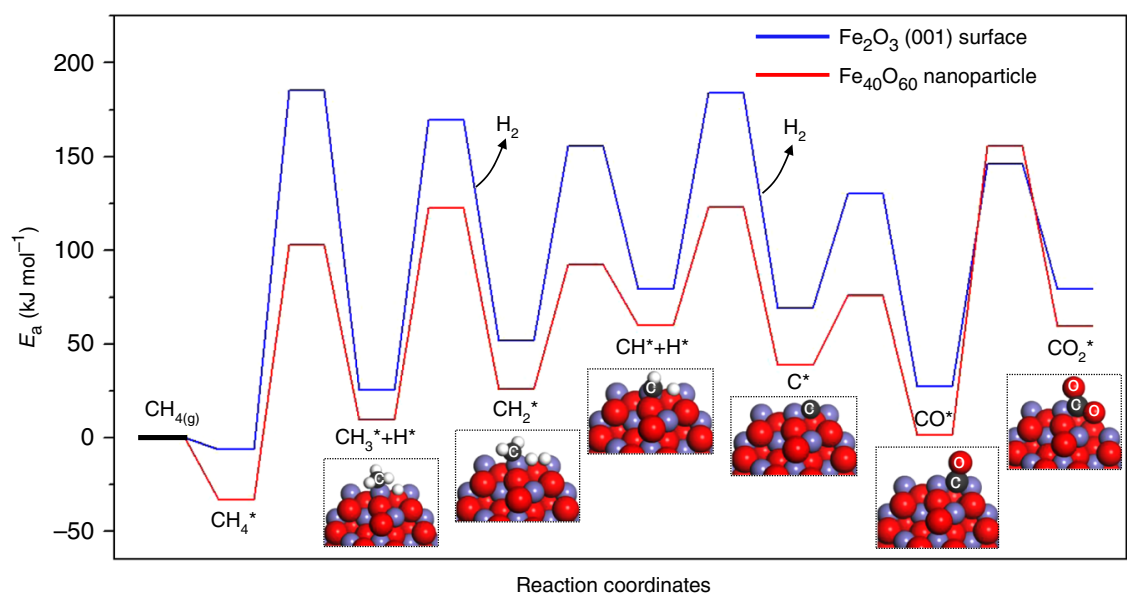

Fig. 5 Energy profile of $\mathrm{CH}_{4}$ partial oxidation on $\mathrm{Fe}_{40} \mathrm{O}_{60}$ nanoparticle and $\mathrm{Fe}_{2} \mathrm{O}_{3}$ (001) surface. 
$\mathrm{Fe}_{40} \mathrm{O}_{60}$ is attributed to the surface stress of nanoparticles, induced by surface atoms with unsaturated coordination. The surface stress leads to shorter and thus stronger $\mathrm{Fe}-\mathrm{O}_{3 \mathrm{C}}$ bonds compared with $\mathrm{Fe}-\mathrm{O}_{3 \mathrm{C}}$ bonds of the $\mathrm{Fe}_{2} \mathrm{O}_{3}$ (001) surface. The formation of $\mathrm{CO}_{2}$ on $\mathrm{Fe}_{40} \mathrm{O}_{60}$ is endothermic, with the calculated reaction energy of $58.2 \mathrm{~kJ} \mathrm{~mol}^{-1}$. These results indicate that the $\mathrm{CO}_{2}$ formation on $\mathrm{Fe}_{40} \mathrm{O}_{60}$ is both kinetically and thermochemically unfavorable. Therefore, $\mathrm{Fe}_{40} \mathrm{O}_{60}$ nanoparticles significantly promote $\mathrm{CO}$ formation while inhibiting $\mathrm{CO}_{2}$ production. Unfortunately, DFT-based calculations of large nanoparticles consisting of a few thousand atoms, required for confirming this conclusion, are intractable to compute even on the most powerful supercomputers. Nevertheless, the experimental evidence for the extraordinary $\mathrm{CO}$ selectivity of $\mathrm{Fe}_{2} \mathrm{O}_{3}$ nanoparticles with the size of $5 \pm 3 \mathrm{~nm}$ indicates that nanostructuring makes $\mathrm{Fe}_{2} \mathrm{O}_{3}$ a more active oxide for $\mathrm{CO}$ production compared with bulk $\mathrm{Fe}_{2} \mathrm{O}_{3}$.

\section{Discussion}

In summary, we demonstrate that $\mathrm{Fe}_{2} \mathrm{O}_{3} @ \mathrm{SBA}-15$ enables near $100 \%$ CO selectivity in chemical looping methane partial oxidation, which is so far the highest value in product selectivity observed for chemical looping systems. Moreover, the effective temperature for syngas generation is lowered to $750-935^{\circ} \mathrm{C}$, which is over $100^{\circ} \mathrm{C}$ lower than current state-of-the-art processes. Nanoscaled oxygen carriers are presented to exhibit little hightemperature reactivity property deterioration and adaptability to broader temperature operating windows for chemical looping operation conditions. These are important factors that can contribute to significant energy-saving reactor designs. The theoretical model and calculations reveal that the structure of the nanoparticles play a key role in $\mathrm{CO}$ selectivity enhancement of $\mathrm{Fe}_{2} \mathrm{O}_{3} @ S B A-15$. The $\mathrm{CH}_{4}$ adsorption energies and $\mathrm{CO}$ formation barriers depend not only on the nanoparticle size but also on the type of surface site exhibited by the nanoparticles. The small average coordination number of $\mathrm{Fe}$ atoms in the nanoparticle facilitates $\mathrm{CH}_{4}$ adsorption and activation due to an upward shift of the $\mathrm{Fe} \mathrm{d}$-band, while the low-coordinated $\mathrm{O}$ atoms greatly promote $\mathrm{Fe}-\mathrm{O}$ bond cleavage and $\mathrm{CO}$ formation, leading to a significant increase in $\mathrm{CO}$ selectivity. These findings contribute to a nanoscale understanding of the underlying metal oxide redox chemistry for chemical looping processes, and provide a systematic strategy toward the design of robust oxygen carrier nanoparticles with superior activity and selectivity.

\section{Methods}

Sample preparation. Surfactant $\mathrm{CTAB}$ and $\mathrm{Fe}\left(\mathrm{NO}_{3}\right)_{3} \cdot 9 \mathrm{H}_{2} \mathrm{O}$ were dissolved in $120 \mathrm{~mL}$ ethanol. $0.4 \mathrm{~g} \mathrm{SBA}-15$ was stirred in the solution for overnight at room temperature. This is followed by a powderization at $90^{\circ} \mathrm{C}$, and then calcination at $600^{\circ} \mathrm{C}$ for $5 \mathrm{~h}$. The prepared sample is marked as $\mathrm{Fe}_{2} \mathrm{O}_{3} @ S B A-15 . \mathrm{Fe}_{2} \mathrm{O}_{3}$ particles without SBA-15 support was also prepared by the same method. For $\mathrm{Fe}_{2} \mathrm{O}_{3} @ S A B-$ 15 , the volume loading was calculated by Eq. (1):

$$
\text { Volume loading }=\frac{m_{\mathrm{Fe}_{2} \mathrm{O}_{3}} / \rho_{\mathrm{Fe}_{2} \mathrm{O}_{3}}}{m_{\mathrm{SBA}-15} \times \text { pore volume }}
$$

where $m_{\mathrm{Fe}_{2} \mathrm{O}_{3}}$ is the total weight of $\mathrm{Fe}_{2} \mathrm{O}_{3}, m_{\mathrm{SBA}-15}$ is total weight of SBA-15, $\rho_{\mathrm{Fe}_{2} \mathrm{O}_{3}}$ is density of $\mathrm{Fe}_{2} \mathrm{O}_{3}$.

Thermogravimetric analysis (TGA). The selectivity of $\mathrm{Fe}_{2} \mathrm{O}_{3} @ S B A-15$ was tested in a SETARAM thermogravimetric analysis (TGA) device. A $20 \mathrm{mg}$ sample was mounted in the TGA, and heated from $750{ }^{\circ} \mathrm{C}$ to $935^{\circ} \mathrm{C}$ with a temperature ramp of $10^{\circ} \mathrm{C} / \mathrm{min} .20 \mathrm{~mL} / \mathrm{min}$ of $\mathrm{CH}_{4}$ balanced with $180 \mathrm{~mL} / \mathrm{min}$ of He was used in the partial oxidation. The outlet gas composition was analyzed by mass spectrometry (MS). 75 redox cycles were also conducted on both samples to test their recyclability. During the methane partial oxidation, $50 \mathrm{~mL} / \mathrm{min}$ of $\mathrm{CH}_{4}$ balanced with $100 \mathrm{~mL} / \mathrm{min}$ of $\mathrm{N}_{2}$ and $50 \mathrm{~mL} / \mathrm{min}$ of $\mathrm{He}$ carrier gases was used in a TGA to react with the sample for $5 \mathrm{~min}$. For the regeneration, $100 \mathrm{~mL} / \mathrm{min}$ of air balanced with $100 \mathrm{~mL} / \mathrm{min}$ of $\mathrm{N}_{2}$ was used to oxidize the sample for $5 \mathrm{~min}$. Between the reduction and the oxidation, $100 \mathrm{~mL} / \mathrm{min}$ of $\mathrm{N}_{2}$ was used as the flushing gas to prevent the mixing of air and methane.
Fixed bed experiment. The methane conversion and syngas selectivity of both unsupported $\mathrm{Fe}_{2} \mathrm{O}_{3}$ and $\mathrm{Fe}_{2} \mathrm{O}_{3} @ S B A-15$ were also evaluated in a quartz U-tube ( $1 \mathrm{~cm}$ diameter) fixed bed reactor. Four different methane weight hourly space velocity (WHSV) of $17.8,25,30,37.5 \mathrm{~mL}\left(\mathrm{mg}_{\mathrm{Fe}_{2} \mathrm{O}_{3}} \mathrm{~h}\right)^{-1}$ were applied to each sample. In the experiment, the solid were amounted in the center of the reactor that is placed in a tube furnace and heated to $800^{\circ} \mathrm{C}$. The outlet gas was analyzed by MS.

Computational details. All plane-wave DFT calculations were performed using the projector augmented wave pseudopotentials provided in the VASP. The Perdew-Burke-Ernzerhof exchange-correlation functional was used with a planewave expansion cutoff of $400 \mathrm{eV}^{23}$. Due to the valence electrons of Fe $3 \mathrm{~d}$ state, the Hubbard $U$ approach was used to correct self-interaction errors of $\alpha-\mathrm{Fe}_{2} \mathrm{O}_{3}{ }^{24,25}$. The increase of $U$ from 1 to $4 \mathrm{eV}$ results in better agreement with the density of states by experimental inverse photoemission spectra ${ }^{26}$. However, a further increase in $U$ will cause Fe 3 d states to shift to unacceptably low energies.

Therefore, $U=4 \mathrm{eV}$ was chosen to describe the energy required for adding an extra $\mathrm{d}$ electron to the $\mathrm{Fe}$ atom. Geometry optimization of the nanoparticle was carried out at the $\Gamma$-point. All atoms were allowed to relax until the ionic forces are smaller than $|0.01| \mathrm{eV} \AA^{-1}$, with a total energy threshold determining the self-consistency of the electron density of $1.0 \times 10^{-5} \mathrm{eV}^{2}$ atom $^{-1}$. Dispersion interactions are modeled using the DFT-D3 method developed by Grimme et al. 27,28 . The calculated $\alpha-\mathrm{Fe}_{2} \mathrm{O}_{3}$ bulk lattice parameters were $a=b=5.04 \AA$ and $c=13.83 \AA$, in good agreement with the experimental values $(a=b=5.038 \AA$ and $c=13.772 \AA)$. The $\alpha-$ $\mathrm{Fe}_{2} \mathrm{O}_{3}(001)$ surface with $\mathrm{Fe}-\mathrm{O}_{3}-\mathrm{Fe}$ - termination was chosen to model the iron oxide slab with a thickness of $\sim 15 \AA^{29}$. $\mathrm{Fe}_{2} \mathrm{O}_{3}$ nanoparticles were modeled by a three-dimensional periodic arrangement with a large cubic cell of $5 \times 5 \times 5 \mathrm{~nm}^{3}$ to minimize lateral interactions. The structures of the free nanoparticles $\left(\mathrm{Fe}_{2} \mathrm{O}_{3}\right)_{n}$ ( $n=4-60)$ were fully optimized without any symmetry constraints. The climbingimage nudged elastic band method ${ }^{30,31}$ is used to locate transition states of elementary steps and map out reaction pathways for $\mathrm{CH}_{4}$ dissociation and oxidation on the $\mathrm{Fe}_{2} \mathrm{O}_{3}$ nanoparticles. The effect of temperature $\left(800^{\circ} \mathrm{C}\right)$ was taken into account for adsorption and reaction barrier comparison.

Characterization methods. The scanning electron microscope measurements were performed with FEI Helios Nanolab 600, with the voltage of $10 \mathrm{kV}$ and the current of $0.17 \mathrm{~mA}$. The TEM images were obtained with a FEI Tecnai G2 30 at $300 \mathrm{kV}$.

The surface area of the sample was analyzed by NOVA 4200e. The sample was first degassed at $300^{\circ} \mathrm{C}$ for over $10 \mathrm{~h}$. Then isothermal $\mathrm{N}_{2}$ adsorption was performed at $-196^{\circ} \mathrm{C}$. The surface area of both SBA- 15 and $\mathrm{Fe}_{2} \mathrm{O}_{3} @ \mathrm{SBA}-15$ was determined by Brunauer-Emmett-Teller method, while the pore size distribution was calculated by Brunauer-Joyner-Halenda method ${ }^{32}$ with adsorption branch.

Small-angle X-ray diffraction was conducted with Rigaku SmartLab equipped with $\mathrm{Cu} \mathrm{K}-\alpha$ radiant. Data were collected from $0.7^{\circ}$ to $3^{\circ}$ with a scanning rate of $0.1^{\circ}$ per minute.

\section{Data availability}

The data that support the findings of this study are available from the corresponding author upon request.

Received: 28 May 2019; Accepted: 7 November 2019; Published online: 03 December 2019

\section{References}

1. Luo, S. et al. Shale gas-to-syngas chemical looping process for stable shale gas conversion to high purity syngas with a $\mathrm{H}_{2}$ : $\mathrm{CO}$ ratio of 2:1. Energy Environ. Sci. 7, 4104-4117 (2014).

2. Fan, L.-S., Zeng, L. \& Luo, S. Chemical-looping technology platform. AIChE J. 61, 2-22 (2015).

3. Qin, L. et al. Enhanced methane monversion in mhemical looping partial oxidation systems using a copper doping modification. Appl. Catal. B 235 143-149 (2018).

4. Zeng, L., Cheng, Z., Fan, J. A., Fan, L.-S. \& Gong, J. Metal oxide redox chemistry for chemical looping processe. Nat. Rev. Chem. 2, 349-364 (2018)

5. Fan, L.-S. Chemical Looping Partial Oxidation: Gasification, Reforming, and Chemical Syntheses, (Cambridge University Press, 2017).

6. Chung, C., Qin, L., Shah, V. \& Fan, L.-S. Chemically and physically robust, commercially-viable iron-based composite oxygen carriers sustainable over 3000 redox cycles at high temperatures for chemical looping applications. Energy Environ. Sci. 10, 2318-2323 (2017).

7. Sun, Z., Ma, T., Tao, H., Fan, Q. \& Han, B. Review: fundamentals and challenges of electrochemical $\mathrm{CO}_{2}$ reduction using two-dimensional materials. Chem 3, 560-587 (2017). 
8. Alalwan, H. A., Mason, S. E., Grassian, V. H. \& Cwiertny, D. M. $\alpha-\mathrm{Fe}_{2} \mathrm{O}_{3}$ nanoparticles as oxygen carriers for chemical looping combustion: an integrated materials characterization approach to understanding oxygen carrier performance, reduction mechanism, and particle size effects. Energy Fuels 32, 7959-7970 (2018).

9. Coleman, N. R. et al. Synthesis and characterization of dimensionally ordered semiconductor nanowires within mesoporous silica. J. Am. Chem. Soc. 123 7010-7016 (2001).

10. Burke, A. M. et al. Large pore bi-functionalised mesoporous silica for metal ion pollution treatment. J. Hazard. Mater. 164, 229-234 (2009).

11. Delaney, P. et al. Development of chemically engineered porous metal oxides for phosphate removal. J. Hazard. Mater. 185, 382-391 (2011).

12. Delaney, P. et al. Porous silica spheres as indoor air pollutant scavengers. $J$. Environ. Monit. 12, 2244-2251 (2010).

13. Barreca, D. et al. Methanolysis of styrene oxide catalysed by a highly efficient zirconium-doped mesoporous silica. Appl. Catal. A 304, 14-20 (2006).

14. Ahern, R. J., Hanrahan, J. P., Tobin, J. M., Ryan, K. B. \& Crean, A. M. Comparison of fenofibratemesoporous silica drug-loading processes for enhanced drug delivery. Eur. J. Pharm. Sci. 50, 400-409 (2013).

15. Abdallah, N. H. et al. Comparison of mesoporous silicate supports for the immobilisation and activity of cytochrome $\mathrm{c}$ and lipase. J. Mol. Catal. B: Enzym. 108, 82-88 (2014).

16. Flynn, E. J., Keane, D. A., Tabari, P. M. \& Morris, M. A. Pervaporation performance enhancement through the incorporation of mesoporous silica spheres into PVA membranes. Sep. Purif. Technol. 118, 73-80 (2013).

17. Kumar, A. et al. Direct air capture of $\mathrm{CO}_{2}$ by physisorbent materials. Angew. Chem., Int. Ed. 54, 14372-14377 (2015).

18. Kresse, G. \& Hafner, J. Ab initio molecular dynamics for liquid metals. Phys. Rev. B 47, 558 (1993).

19. Kresse, G. \& Furthmüller, J. Efficiency of ab-initio total energy calculations for metals and semiconductors using a plane-wave basis set. Comput. Mater. Sci. 6, 15-50 (1996).

20. Kresse, G. \& Furthmüller, J. Efficient iterative schemes for ab initio totalenergy calculations using a plane-wave basis set. Phys. Rev. B 54, 11169 (1996).

21. Cheng, Z., Qin, L., Guo, M., Fan, J. A. \& Fan, L.-S. Methane adsorption and dissociation on iron oxide oxygen carrier: role of oxygen vacancy. Phys. Chem. Chem. Phys. 18, 16423-16435 (2016).

22. Cheng, Z. et al. Oxygen vacancy promoted methane partial oxidation over iron oxide oxygen carrier in chemical looping process. Phys. Chem. Chem. Phys. 18, 32418-32428 (2016).

23. Perdew, J. P., Burke, K. \& Ernzerhof, M. Generalized gradient approximation made simple. Phys. Rev. Lett. 77, 3865 (1996).

24. Herbst, J., Watson, R. \& Wilkins, J. Relativistic calculations of 4 f excitation energies in the rare-earth metals: further results. Phys. Rev. B 17, 3089 (1978).

25. Anisimov, V. \& Gunnarsson, O. Density-functional calculation of effective Coulomb interactions in metals. Phys. Rev. B 43, 7570 (1991).

26. Rollmann, G., Rohrbach, A., Entel, P. \& Hafner, J. First-principles calculation of the structure and magnetic phases of hematite. Phys. Rev. B 69, 165107 (2004).

27. Grimme, S., Antony, J., Ehrlich, S. \& Krieg, H. A consistent and accurate ab initio parametrization of density functional dispersion correction (DFT-D) for the 94 elements H-Pu. J. Chem. Phys. 132, 19 (2010).

28. Grimme, S., Ehrlich, S. \& Goerigk, L. Effect of the damping function in dispersion corrected density functional theory. J. Comput. Chem. 32, 1456-1465 (2011).

29. Qin, L., Cheng, Z., Guo, M., Fan, J. A. \& Fan, L.-S. The impact of $1 \%$ lanthanum dopant oncarbonaceous fuel redox reaction with iron based oxygen carrier in chemical looping processes. ACS Energy Lett. 2, 70-74 (2017).
30. Sheppard, D. \& Henkelman, G. Paths to which the nudged elastic band converges. J. Comput. Chem. 32, 1769-1771 (2011).

31. Henkelman, G., Uberuaga, B. P. \& Jónsson, H. Climbing image nudged elastic band method for finding saddle points and minimum energy paths. J. Chem. Phys. 113, 9901-9904 (2000).

32. Li, B. \& Zhang, S. Methane reforming with $\mathrm{CO}_{2}$ using nickel catalysts supported on yttria-doped SBA-15 mesoporous materials via sol-gel process. Int. J. Hydrog. Energy 38, 14250-14260 (2013).

\section{Acknowledgements}

The service support provided by the Center for Electron Microscopy and the Analysis and NanoSystem Laboratory at The Ohio State University and the computing support provided by the Ohio Supercomputer Center are gratefully acknowledged.

\section{Author contributions}

Y.L. performed TEM, SEM, EDX, TGA redox experiments, TPR, and fixed bed experiments. L.Q. designed the experiments. Y.L., L.Q., J.W.G., and F.K. analyzed data. Z.C. performed the DFT calculation and analyzed the mechanism. J.W.G. did the sample synthesis and surface and pore size analysis. F.K. performed SAXRD experiments. J.A.F. discussed the results and commented on the manuscript. L.S.F. supervised the research. All authors participated in manuscript preparation, data interpretation and discussions

\section{Competing interests}

The authors declare no competing interests.

\section{Additional information}

Supplementary information is available for this paper at https://doi.org/10.1038/s41467019-13560-0.

Correspondence and requests for materials should be addressed to L.-S.F.

Peer review information Nature Communications thanks the anonymous reviewers for their contribution to the peer review of this work.

Reprints and permission information is available at http://www.nature.com/reprints

Publisher's note Springer Nature remains neutral with regard to jurisdictional claims in published maps and institutional affiliations.

Open Access This article is licensed under a Creative Commons Attribution 4.0 International License, which permits use, sharing, adaptation, distribution and reproduction in any medium or format, as long as you give appropriate credit to the original author(s) and the source, provide a link to the Creative Commons license, and indicate if changes were made. The images or other third party material in this article are included in the article's Creative Commons license, unles indicated otherwise in a credit line to the material. If material is not included in the article's Creative Commons license and your intended use is not permitted by statutory regulation or exceeds the permitted use, you will need to obtain permission directly from the copyright holder. To view a copy of this license, visit http://creativecommons.org/ licenses/by/4.0/.

(C) The Author(s) 2019 